Original Research Paper

\title{
Essential Oils from The Dropped Flowers of Camellia japonica: Extraction Optimization, Chemical Profile and Antibacterial Property
}

\author{
Yunqi Kong, Gaochao Wang, Xinyu Wang, Tong Wang, \\ Jieyang Shen, Aibei Zhang, Lixue Zheng and Yang Zhang* \\ School of Biology and Food Engineering, Changshu Institute of Technology, Changshu 215500, Jiangsu, China
}

\author{
Article history \\ Received: 30-11-2020 \\ Revised: 25-01-2021 \\ Accepted: 27-01-2021 \\ Corresponding Author: \\ Yang Zhang \\ School of Biology and Food \\ Engineering, Changshu \\ Institute of Technology, \\ Changshu 215500, Jiangsu, \\ China \\ E-mail: zhangyang@cslg.edu.cn
}

These authors contributed equally

\begin{abstract}
Camellia japonica is one of the most economically valuable species that can be taxonomically placed in the Theaceae family. Many horticultural varieties of $C$. japonica have been cultivated as ornamental trees worldwide, owing to their charming flowers. However, young $C$. japonica flowers usually drop in a "decapitated" form during the peak flowering stage, causing a resource waste. In this study, Essential Oils from the Dropped $C$. japonica Flowers (EODCJF) were extracted with hydrodistillation and process was optimized by response surface methodology. The chemical profile and antibacterial activity were tested by gas chromatography-mass spectrometry and by disc diffusion, respectively. The optimal extraction parameters were: Immersion time of $9 \mathrm{~h}$, extraction time of $8 \mathrm{~h}$ and liquid-to-solid ratio of 39: $1(\mathrm{~mL} / \mathrm{g})$, under these conditions, the yield was $3.20 \%$. The actual yield was in compliance with the predicted result with an error margin of $3.61 \%$. Thirty-three volatile compounds accounting for $94.46 \%$ were authenticated in EODCJF with alkanes of $53.96 \%$ and alcohols of $28.59 \%$, respectively. EODCJF exerted certain antibacterial capacities against Staphylococcus aureus, Escherichia coli, Bacillus subtilis and Bacillus pumilus. Their antibacterial activities could be contributed by the long-chain alcohols in EODCJF and alkanes may potentiate the dispersion of these liposoluble alcohols in EODCJF.
\end{abstract}

Keywords: Essential Oils, Dropped Camellia japonica Flowers, Extraction Optimization, Chemical Profile, Antibacterial Activity

\section{Introduction}

Essential Oils (EOs) are a kind of secondary metabolites in plants. They usually comprise diverse components that bear smaller molecular weights and aromatic odors (Zhang et al., 2018a). According to the chemical profile difference, EOs can be classified into aromatics, aliphatics and terpenoids, most of which are featured by a higher volatility and a lower boiling point (Tian et al., 2019). EOs exert a series of bioactivities, such as antioxidant (Imane et al., 2020), antitumor (Andrade et al., 2018), antimicrobial (Zhang et al., 2018b), anti-inflammatory (Sen et al., 2019) and immunomodulatory (Valdivieso-Ugarte et al., 2019) properties. Thus the search for novel bioactive EOs remains ongoing concern.

The genus Camellia is native to Southeast Asia and China. Up to now, approximately 280 species of
Camellia have been found to be placed in the Theaceae family taxonomically, such as Camellia sinensis var. sinensis, Camellia sinensis var. assamica, Camellia japonica, Camellia oleifera, Camellia chrysantha and Camellia reticulate ( $\mathrm{Li}$ et al., 2019). Among them, C. japonica is one of the most economically valuable species. Many horticultural varieties of $C$. japonica have been developed as ornamental trees worldwide, due to the beautiful and charming flowers (Kim et al., 2019; Páscoa et al., 2019). In addition to horticultural application, $C$. japonica and its principles elicit various beneficially physiological and pharmacological effects. The ethanol extract from flowers of $C$. japonica exerts antioxidant capacity via scavenging excessive free radicals and reactive oxygen species and via elevating activities of antioxidases (Piao et al., 2011). The quercetin glycosides, gallic acid and its glucoside conjugates isolated from the hot water extract of $C$. 
japonica flowers show higher 1, 1-Diphenyl-2Picrylhydrazyl (DPPH) radical-scavenging capacity than those of other compounds, indicating that the antioxidant activity of $C$. japonica flowers could be chiefly contributed by these bioactive phenolic acids and flavonoid glycosides (Lee et al., 2011). The Oleanane triterpenes isolated from C. japonica flowers exhibit inhibitory effects against the replication of porcine epidemic diarrhea virus (Yang et al., 2015) and the methanol extracts from the leaves and flowers of $C$. japonica display certain inhibitory effects against some food-borne pathogen and food spoilage bacteria (Lee et al., 2005). However, to the best of our knowledge, there is little information on the research about the essential oils from $C$. japonica flowers.

Unlike other ornamental flowers, $C$. japonica flowers usually drop in a young "decapitated" form during the peak flowering stage, which causes a tremendous waste of this resource. In present work, Essential Oils from the Dropped C. japonica Flowers (EODCJF) were extracted for The first time and the extraction process was optimized. After characterization, the antibacterial potential was appraised. It is hoped that this study will highlight the comprehensive development and utilization of dropped $C$. japonica flowers.

\section{Materials and Methods}

\section{Materials}

The dropped $C$. japonica flowers were collected from April to June 2020 in the campus of Changshu Institute of Technology (Changshu, Jiangsu, China) and authenticated by Dr. Zhumei Cui, School of Biology and Food Engineering, Changshu Institute of Technology. After being dried at $50-60^{\circ} \mathrm{C}$, the dried $C$. japonica flowers were deposited at the School of Biology and Food Engineering, Changshu Institute of Technology with a voucher number of SW-2020-068. Before the experiment began, dried $C$. japonica flowers were sheared and sieved to 40-mesh.

All the reagents and solvents involved were purchased from Shanghai Aladdin Bio-Chem Technology Co., Ltd (Shanghai, China) and were of analytical grade.

All the bacterial strains, including Staphylococcus aureus (ATCC 49775), Escherichia coli (ATCC 33456), Bacillus subtilis (ATCC 6633) and Bacillus pumilus (ATCC 7065) were from ATCC Global Bioresource Center (Manassas, VA, USA) and stored at $-80^{\circ} \mathrm{C}$ in $30 \%$ (v/v) glycerol media.

\section{Essential Oils Extraction}

Essential Oils from the Dropped C. japonica Flowers (EODCJF) were extracted with hydrodistillation method in a Clevenger-type apparatus (Memarzadeh et al., 2015). Twenty grams of dried powders of $C$. japonica flowers were immersed in a certain volume of distilled water for several hours. After a certain time of extraction starting from water boiling, EODCJF were obtained and then stored at $0^{\circ} \mathrm{C}$ in a sealed vial. The extraction yield $(w / w, \%)$ was calculated according to the following formula:

$$
Y(w / w, \%)=W_{1}(\mathrm{~g}) / W_{2}(\mathrm{~g}) \times 100
$$

Where:

$$
\begin{aligned}
& Y(w / w, \%)=\text { Extraction yield of EODCJF }(w / w, \%) \\
& W_{1} \quad=\text { The weight of obtained essential oils }(g) \\
& W_{2} \quad=\text { The weight of dried powders of } C \text {. } \\
& \text { japonica flowers }(\mathrm{g})
\end{aligned}
$$

\section{Experimental Design for Extraction Optimization}

First, single-factor experiment was performed to assess the effects of three independent variables, including immersion time $(2-12 \mathrm{~h})$, liquid-to-solid ratio (10-60: $1 \mathrm{~mL} / \mathrm{g})$ and extraction time $(2-12 \mathrm{~h})$ on EODCJF yield. Then, the extraction process was optimized with Response Surface Methodology (RSM) (Cui et al., 2018). A three-factor-three-level Box-Behnken Design (BBD) encompassing seventeen runs was applied at the center point (Table 1).

Regression analysis was conducted to analyze data and fitted to the second-order polynomial model as below:

$$
Y=\beta_{O}+\sum_{i=1}^{4} \beta_{i} X_{i}+\sum_{i=1}^{4} \beta_{i i} X_{i}^{2}+\sum_{i=1}^{3} \sum_{j=i+1}^{4} \beta_{i j} X_{i} Y_{j}
$$

Where:

$$
\begin{array}{ll}
Y & =\text { The predicted extraction yield of EODCJF } \\
\beta_{0} & =\text { An intercept } \\
\beta_{i} & =\text { The linear coefficient } \\
\beta_{i i} & =\text { The quadratic coefficient } \\
\beta_{i j} & =\text { The interactive term } \\
X_{i} \text { and } X_{j} & =\text { The coded independent variables }
\end{array}
$$

\section{The Chemical Profile of Essential Oils}

The chemical composition of EODCJF was determined by a gas chromatography-mass spectrometry (GCMS-QP2010, Shimadzu, Kyoto, Japan) equipped with a Rxi-5Sil MS column $(30 \mathrm{~m} \times 0.25 \mathrm{~mm}$ ID, 0.25 $\mu \mathrm{m}$ of film thickness) and interfaced with an ion trap detector. Analysis was operated under the following conditions: (1) Helium was adopted as the carrier gas at a flow rate of $1.0 \mathrm{~mL} / \mathrm{min}$. (2) Temperatures of transfer line and ion trap were set as 250 and $230^{\circ} \mathrm{C}$, respectively. (3) Column temperature was initially raised from 40 to $60^{\circ} \mathrm{C}$ at $5^{\circ} \mathrm{C} / \mathrm{min}$ and kept for $2 \mathrm{~min}$, then elevated to $110^{\circ} \mathrm{C}$ at $15^{\circ} \mathrm{C} / \mathrm{min}$ and held for $4 \mathrm{~min}$, from 110 to $180^{\circ} \mathrm{C}$ at $5^{\circ} \mathrm{C} / \mathrm{min}$ and maintained for $2 \mathrm{~min}$, finally increased up to $280^{\circ} \mathrm{C}$ at $25^{\circ} \mathrm{C} / \mathrm{min}$ and kept for $5 \mathrm{~min}$. One microliter of EODCJF diethyl ether solution at concentration of 10 
$\mathrm{mg} / \mathrm{mL}$ was injected into the analyzer at a split ratio of 1: 30 under a scan range of 35-500 amu and an electron ionization energy of $70 \mathrm{eV}$. Compound identification was assigned by referring the retention index of $n$ alkanes $\left(\mathrm{C}_{8}-\mathrm{C}_{40}\right)$ standards and by comparing the mass spectrum with NIST 05 database or with reported literatures (Tian et al., 2019).

\section{The Antibacterial Activity of Essential Oils}

The paper disks with diameter of $6 \mathrm{~mm}$ were soaked by EODCJF in Dimethyl Sulfoxide (DMSO) and placed on the surface of solid medium that had been inoculated with the test bacteria ( $S$. aureus, E. coli, B. subtilis and B. pumilus) at $6.0 \log \mathrm{CFU} / \mathrm{mL}$. Normal saline in Dimethyl Sulfoxide (DMSO) and chloramphenicol in DMSO were served as negative and positive controls, respectively. All the solid medium plates were cultured at $37^{\circ} \mathrm{C}$ for $24 \mathrm{~h}$. Diameter of inhibition zones was recorded (Zhang et al., 2018b).

\section{Statistical Analysis}

Extraction optimization was designed and analyzed with a Design-Expert software 8.0.6.1 (Stat-Ease, Minneapolis, MN, USA). Experimental data was represented as means or means \pm SD (standard deviation). SPSS19.0 Software (SPSS Inc., Chicago, USA) was used to appraise the statistical difference. The significance of distances between means was evaluated with $t$-test and one-way Analysis Of Variance (ANOVA).

\section{Results}

\section{The Single-Factor Experiments for EODCJF} Extraction

\section{Effects of Immersion Time on Yield}

As shown in Fig. 1, when liquid-to-solid ratio and extraction time were fixed as 40: $1(\mathrm{~mL} / \mathrm{g})$ and $8 \mathrm{~h}$, respectively, EODCJF yield increased with the prolongation of immersion time ranging from 2 to $8 \mathrm{~h}$, but when immersion time exceeded $8 \mathrm{~h}$, yield decreased. The optimal immersion time was $8 \mathrm{~h}$.

\section{Effects of Extraction Time on Yield}

Fix liquid-to-solid ratio of 40: $1(\mathrm{~mL} / \mathrm{g})$ and immersion time of $8 \mathrm{~h}$ to explore the effects of extraction time on yield. As shown in Fig. 2, in the range of 2-8 h, EODCJF yield was raised with the increase of extraction time, maximized to $2.83 \pm 0.12 \%$ at $8 \mathrm{~h}$ and then declined with lengthening extraction time.

\section{Effect of Liquid-to-Solid Ratio on Yield}

As shown in Fig. 3, when immersion time and extraction time were all set as $8 \mathrm{~h}$, EODCJF yield was heightened within the liquid-to-solid ratio of 10:1 $(\mathrm{mL} / \mathrm{g})-40: 1(\mathrm{~mL} / \mathrm{g})$, maximized to $3.3 \pm 0.1 \%$ at the ratio of 40: $1(\mathrm{~mL} / \mathrm{g})$ and then dropped with the elevation of liquid-to-solid ratio.

\section{The Extraction Optimization of EODCJF with RSM}

Based on principles of BBD, according to the results of single-factor experiments, three independent variables, including immersion time $\left(\mathrm{h}, X_{1}\right)$, extraction time $\left(\mathrm{h}, X_{2}\right)$ and liquid-to-solid ratio $\left(\mathrm{mL} / \mathrm{g}, X_{3}\right)$ were selected and applied to RSM optimization with EODCJF extraction yield as response variable. Seventeen possible orderings and response values were achieved and represented in Table 2. It can be observed that the EODCJF yields were within a range of $1.88-3.30 \%$, which can be described by the following second-order polynomial equation:

$$
\begin{aligned}
& Y=3.26+0.29 X_{1}+0.13 X_{2}-0.032 X_{3}+0.11 X_{1} X_{2} \\
& -0.04 X_{1} X_{3}-0.02 X_{2} X_{3}-0.44 X_{1}{ }^{2}-0.68 X_{2}{ }^{2}-0.33 X_{3}{ }^{2}
\end{aligned}
$$

Where:

$Y=$ EODCJF yield (w/w, \%)

$X_{1}=$ The immersion time (h)

$X_{2}=$ The extraction time $(\mathrm{h})$

$X_{3}=$ Liquid-to-solid ratio $(\mathrm{mL} / \mathrm{g})$

The one-way Analysis Of Variance (ANOVA) for fitted equation was shown in Table 3. For the source of model, the high $F$-value (148.11) and low $P$-value $(<0.0001)$ demonstrated that the obtained model is highly significant and the regression equation is desirable (Cheng et al., 2017). The determination coefficient of model $\left(\mathrm{R}^{2}\right)$ and adjusted coefficient $\left(\right.$ Adj $R^{2}$ ) were 0.9948 and 0.9881 , respectively. These values implied that the accuracy of model is sufficient to interpret $98.81 \%$ of the total variability of model response. For lack of fit, the $F$-value and $P$-value were all greater than 0.05 , indicating a non-significance, which further validated the model. The linear terms $X_{1}$ and $X_{2}$ were highly significant $(P<0.01)$ and $X_{3}$ was not significant $(P>0.05)$. The quadratic parameters $X_{1}^{2}, X_{2}^{2}$ and $X_{3}^{2}$ were all highly significant $(P<0.01)$. The interaction parameters $X_{1} X_{2}$ were highly significant $(P<0.01)$, but $X_{1} X_{3}$ and $X_{2} X_{3}$ were not significant $(P>0.05)$.

To better understand the interaction effects between two independent variables, the contour plots (Figs. 4 to 6) were achieved by RSM. From Fig. 4, it can be clearly seen that the increase in immersion time or extraction time potentiated the improvement of EODCJF yield. In Fig. 5, EODCJF yield increased with the increase of immersion time or liquid-to-solid ratio in the initial stage, but experienced a slow elevation with the further increase of any parameters. From Fig. 6, we can observe that EODCJF yield was raised with increasing extraction time or liquidto-solid ratio at first, but obviously descended afterwards. These results and trends were consistent with those of single-factor experiments. 
The optimized extraction parameters obtained from Design-Expert 8.0.6.1 were as follows: Immersion time of $8.69 \mathrm{~h}$, extraction time of $8.24 \mathrm{~h}$, liquid-to-solid ratio of 39.26: $1(\mathrm{~mL} / \mathrm{g})$ and the predicted yield was $3.32 \%$. In order to facilitate practical operation, the predicted optimal conditions were further modified as: Immersion time of $9 \mathrm{~h}$, extraction time of $8 \mathrm{~h}$ and liquid-to-solid ratio of 39: $1(\mathrm{~mL} / \mathrm{g})$, under which the actual yield was $3.20 \%$. The actual results were in line with the predicted data with an error margin of $3.61 \%$.

\section{The Chemical Profile of EODCJF}

As shown in Table 4, thirty-three volatile compounds accounting for $94.46 \%$ were authenticated in EODCJF with GC-MS. It can be noted that EODCJF are abundant in alkanes and alcohols, corresponding to 53.96 and $28.59 \%$ of the total amount, respectively. $N$-tetracosane was the volatile compound with highest content identified in EODCJF (27.7\%), followed by 1-tetracosanol (14.3\%), $N$-nonacosane $(9.03 \%)$ and phytol $(7.92 \%)$.

\section{The In Vitro Antibacterial Activity of EODCJF}

As shown in Table 5 and Fig. 7, EODCJF elicited certain antibacterial capacities against $E$. coli, $B$. pumilus, B. subtilis and $S$. aureus. The inhibition zone diameters of EODCJF against these test bacteria were larger than those of normal control, but smaller than those of positive control, indicating that the antibacterial activities of EODCJF against these bacteria are inferior to those of chloramphenicol, a well-known chemically obtained antibacterial agent.

Table 2: Box-Behnken design and observed responses

\begin{tabular}{lcccc}
\hline & Independent variables & & & \\
Run & $-X_{1}$ & $X_{3}$ & \\
\hline 1 & 1 & $X_{2}$ & 0 & 2.60 \\
2 & -1 & 1 & -1 & 2.17 \\
3 & 0 & 0 & -1 & 2.10 \\
4 & 0 & -1 & 0 & 3.27 \\
5 & 0 & 0 & 1 & 2.10 \\
6 & 0 & -1 & 0 & 3.20 \\
7 & -1 & 0 & 1 & 2.16 \\
8 & 1 & 0 & 0 & 2.17 \\
9 & -1 & -1 & 0 & 1.90 \\
10 & 0 & -1 & 0 & 3.30 \\
11 & 0 & 0 & 0 & 3.27 \\
12 & 1 & 0 & 1 & 2.73 \\
13 & 1 & 0 & -1 & 2.90 \\
14 & 0 & 0 & -1 & 2.44 \\
15 & 0 & 1 & 1 & 3.26 \\
16 & 0 & 1 & 0 & 1.88 \\
\hline
\end{tabular}

Table 3: Test of significance for regression coefficients ${ }^{\mathrm{a}}$

\begin{tabular}{|c|c|c|c|c|c|}
\hline$\overline{\text { Source }^{b}}$ & Sum of Squares & Mean Square & $F$-Value & $P$-Value & Significance $^{\mathrm{c}}$ \\
\hline Model & 4.41 & 0.49 & 148.11 & $<0.0001$ & *** \\
\hline$X_{1}$ & 0.66 & 0.66 & 198.00 & $<0.0001$ & ** \\
\hline$X_{2}$ & 0.13 & 0.13 & 38.52 & 0.0004 & *** \\
\hline$X_{3}$ & $8.45 \times 10^{-3}$ & $8.45 \times 10^{-3}$ & 2.55 & 0.1542 & n.s. \\
\hline$X_{1} X_{2}$ & 0.051 & 0.051 & 15.29 & 0.0058 & ${ }^{* *}$ \\
\hline$X_{1} X_{3}$ & $6.40 \times 10^{-3}$ & $6.40 \times 10^{-3}$ & 1.93 & 0.2070 & n.s. \\
\hline$X_{2} X_{3}$ & $1.60 \times 10^{-3}$ & $1.60 \times 10^{-3}$ & 0.48 & 0.5094 & n.s. \\
\hline$X_{1}^{2}$ & 0.82 & 0.82 & 247.62 & $<0.0001$ & ** \\
\hline$X_{2}^{2}$ & 1.95 & 1.95 & 590.24 & $<0.0001$ & ** \\
\hline$X_{3}^{2}$ & 0.46 & 0.46 & 137.45 & $<0.0001$ & ** \\
\hline Residual & 0.023 & $3.31 \times 10^{-3}$ & & & \\
\hline Lack of Fit & 0.018 & $5.93 \times 10^{-3}$ & 4.39 & 0.0935 & n.s. \\
\hline Pure Error & $5.40 \times 10^{-3}$ & $1.35 \times 10^{-3}$ & & & \\
\hline Cor Total & 4.44 & & & & \\
\hline R-Squared & 0.9948 & & & & \\
\hline Adj R-Squared & 0.9881 & & & & \\
\hline
\end{tabular}


Table 4: The chemical compositions of EODCJF

\begin{tabular}{|c|c|c|c|c|c|}
\hline No. & Compound & RI & $\mathrm{RI}^{*}$ & Molecular formula & Content $(\%)$ \\
\hline 1 & $\begin{array}{l}\text { 1-(2-Hydroxy-5-methylphenyl) } \\
\text { ethanone }\end{array}$ & 1363 & 1419 & $\mathrm{C}_{9} \mathrm{H}_{10} \mathrm{O}_{2}$ & 0.21 \\
\hline 2 & $N$-Octadecane & 1810 & 1812 & $\mathrm{C}_{18} \mathrm{H}_{38}$ & 0.12 \\
\hline 3 & $N$-Nonadecane & 1910 & 1906 & $\mathrm{C}_{19} \mathrm{H}_{40}$ & 0.09 \\
\hline 4 & Stearaldehyde & 1999 & 1911 & $\mathrm{C}_{18} \mathrm{H}_{36} \mathrm{O}$ & 0.57 \\
\hline 5 & 2-Nonadecanone & 2045 & 2052 & $\mathrm{C}_{19} \mathrm{H}_{38} \mathrm{O}$ & 0.12 \\
\hline 6 & Dibutyl phthalate & 2037 & 2077 & $\mathrm{C}_{16} \mathrm{H}_{22} \mathrm{O}_{4}$ & 0.12 \\
\hline 7 & Dioctyl ether & 2146 & 2170 & $\mathrm{C}_{16} \mathrm{H}_{34} \mathrm{O}$ & 0.16 \\
\hline 8 & Ethyl stearate & 2177 & 2196 & $\mathrm{C}_{20} \mathrm{H}_{40} \mathrm{O}_{2}$ & 0.09 \\
\hline 9 & Tetraprenol & 2192 & 2203 & $\mathrm{C}_{20} \mathrm{H}_{34} \mathrm{O}$ & 1.18 \\
\hline 10 & Phytol & 2208 & 2219 & $\mathrm{C}_{20} \mathrm{H}_{40} \mathrm{O}$ & 7.92 \\
\hline 11 & Cycloheptadecanol & 2226 & 2228 & $\mathrm{C}_{17} \mathrm{H}_{34} \mathrm{O}$ & 0.20 \\
\hline 12 & Ambrettolid & 2246 & 2272 & $\mathrm{C}_{16} \mathrm{H}_{28} \mathrm{O}_{2}$ & 0.16 \\
\hline 13 & Muscalure & 2315 & 2379 & $\mathrm{C}_{23} \mathrm{H}_{46}$ & 0.86 \\
\hline 14 & Dioctyl fumarate & 2395 & 2387 & $\mathrm{C}_{20} \mathrm{H}_{36} \mathrm{O}_{4}$ & 0.20 \\
\hline 15 & $N$-Octadecane & 2413 & 2453 & $\mathrm{C}_{18} \mathrm{H}_{38}$ & 0.29 \\
\hline 16 & Henicosyl formate & 2472 & 2477 & $\mathrm{C}_{22} \mathrm{H}_{44} \mathrm{O}_{2}$ & 5.43 \\
\hline 17 & $N$-Pentacosane & 2506 & 2501 & $\mathrm{C}_{25} \mathrm{H}_{52}$ & 6.11 \\
\hline 18 & Erucic acid & 2572 & 2532 & $\mathrm{C}_{22} \mathrm{H}_{42} \mathrm{O}_{2}$ & 0.36 \\
\hline 19 & $N$-Eicosane & 2605 & 2568 & $\mathrm{C}_{20} \mathrm{H}_{42}$ & 0.64 \\
\hline 20 & 9-Hexacosene & 2614 & 2580 & $\mathrm{C}_{26} \mathrm{H}_{52}$ & 2.39 \\
\hline 21 & $N$-Tetracosane & 2637 & 2603 & $\mathrm{C}_{24} \mathrm{H}_{50}$ & 27.7 \\
\hline 22 & 1-Tetracosanol & 2681 & 2650 & $\mathrm{C}_{24} \mathrm{H}_{50} \mathrm{O}$ & 14.3 \\
\hline 23 & Squalane & 2702 & 2714 & $\mathrm{C}_{30} \mathrm{H}_{62}$ & 0.40 \\
\hline 24 & 1-Pentacosanol & 2772 & 2802 & $\mathrm{C}_{25} \mathrm{H}_{52} \mathrm{O}$ & 3.48 \\
\hline 25 & Ditetradecyl ether & 2880 & 2850 & $\mathrm{C}_{28} \mathrm{H}_{58} \mathrm{O}$ & 0.14 \\
\hline 26 & $N$-Nonacosane & 2924 & 2902 & $\mathrm{C}_{29} \mathrm{H}_{60}$ & 9.03 \\
\hline 27 & Squalene & 2951 & 2912 & $\mathrm{C}_{30} \mathrm{H}_{50}$ & 1.10 \\
\hline 28 & $N$-Triacontane & 3003 & 2918 & $\mathrm{C}_{30} \mathrm{H}_{62}$ & 2.97 \\
\hline 29 & 1-Octacosanol & 3047 & 3036 & $\mathrm{C}_{28} \mathrm{H}_{58} \mathrm{O}$ & 0.74 \\
\hline 30 & $N$-Dotriacontane & 3102 & 3079 & $\mathrm{C}_{32} \mathrm{H}_{66}$ & 4.58 \\
\hline 31 & 1-Triacontanol & 3246 & 3107 & $\mathrm{C}_{30} \mathrm{H}_{62} \mathrm{O}$ & 0.77 \\
\hline 32 & $N$-Tritriacontane & 3283 & 3274 & $\mathrm{C}_{33} \mathrm{H}_{68}$ & 1.87 \\
\hline 33 & $N$-Tetratriacontane & 3312 & 3298 & $\mathrm{C}_{34} \mathrm{H}_{70}$ & 0.16 \\
\hline Total & 94.46 & & & & \\
\hline Alkanes & 53.96 & & & & \\
\hline Alcohols & 28.59 & & & & \\
\hline Carboxyl acids and esters & 6.36 & & & & \\
\hline Alkenes & 4.35 & & & & \\
\hline Others & 1.20 & & & & \\
\hline
\end{tabular}

RI: Retention Index from NIST 05 database; RI*: Retention Index reckoned by referring to that of $\mathrm{C}_{8}$ - $\mathrm{C}_{40} n$-alkanes standard. EODCJF: Essential Oils from the Dropped C. japonica Flowers

Table 5: The in vitro antibacterial activity of EODCJF

\begin{tabular}{|c|c|c|c|}
\hline \multirow[b]{2}{*}{ Bacteria } & \multicolumn{3}{|c|}{ Diameters of inhibition zone (mm) } \\
\hline & EODCJF & $\mathrm{NC}$ & $\mathrm{PC}$ \\
\hline E. coli & 7.8 & n.d. & 10.9 \\
\hline B. pumilus & 7.5 & n.d. & 9.2 \\
\hline B. subtilis & 7.4 & n.d. & 8.9 \\
\hline S. aureus & 7.2 & n.d. & 8.0 \\
\hline
\end{tabular}

Data were expressed as the means $(\mathrm{n}=3)$. EODCJF: Essential Oils from the Dropped $C$. japonica Flowers; NC: Normal Control (normal saline); PC: Positive Control (chloramphenicol); n.d.: Not detected 


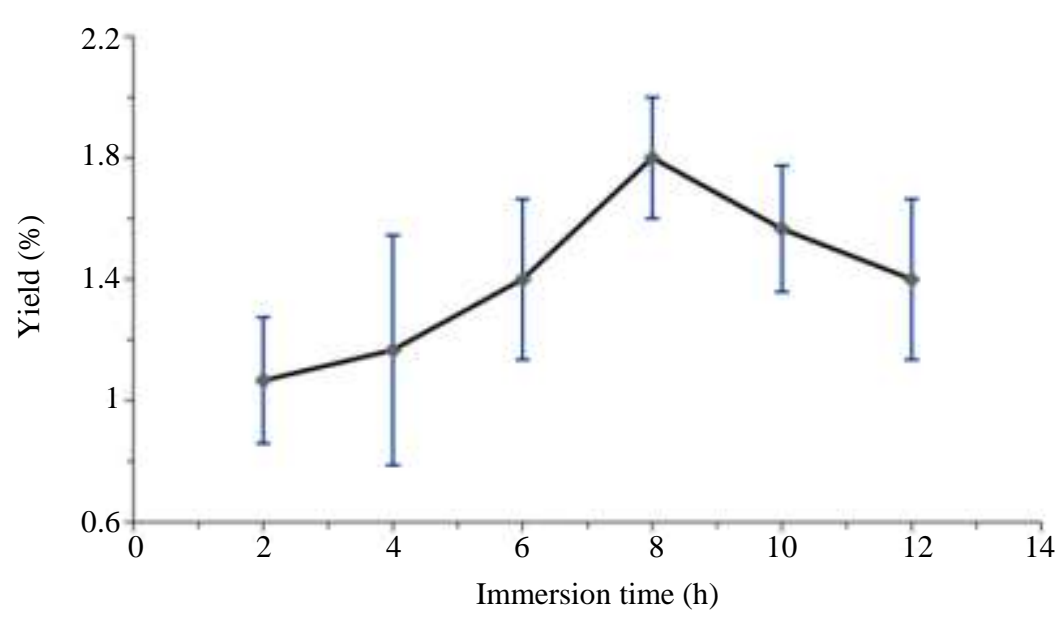

Fig. 1: Effects of immersion time on yield

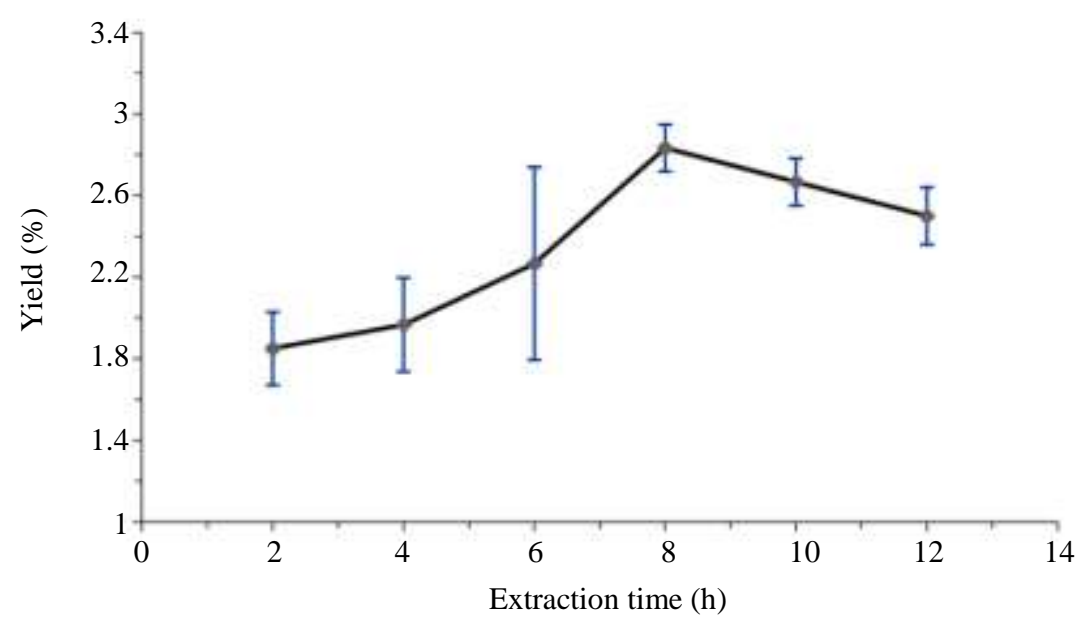

Fig. 2: Effects of extraction time on yield

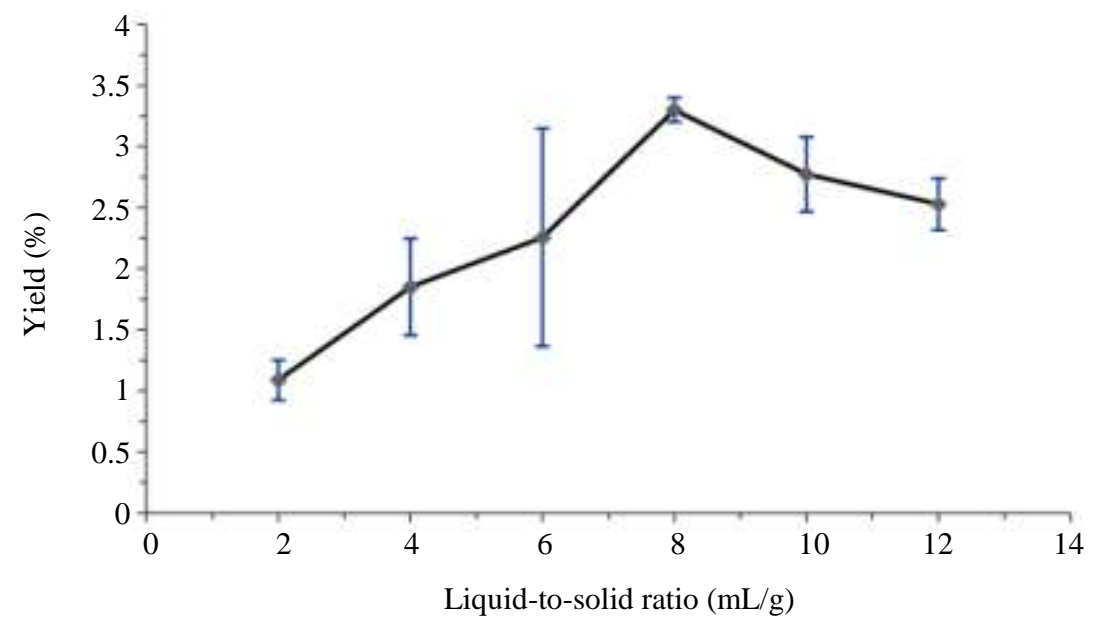

Fig. 3: Effects of liquid-to-solid ratio on yield 


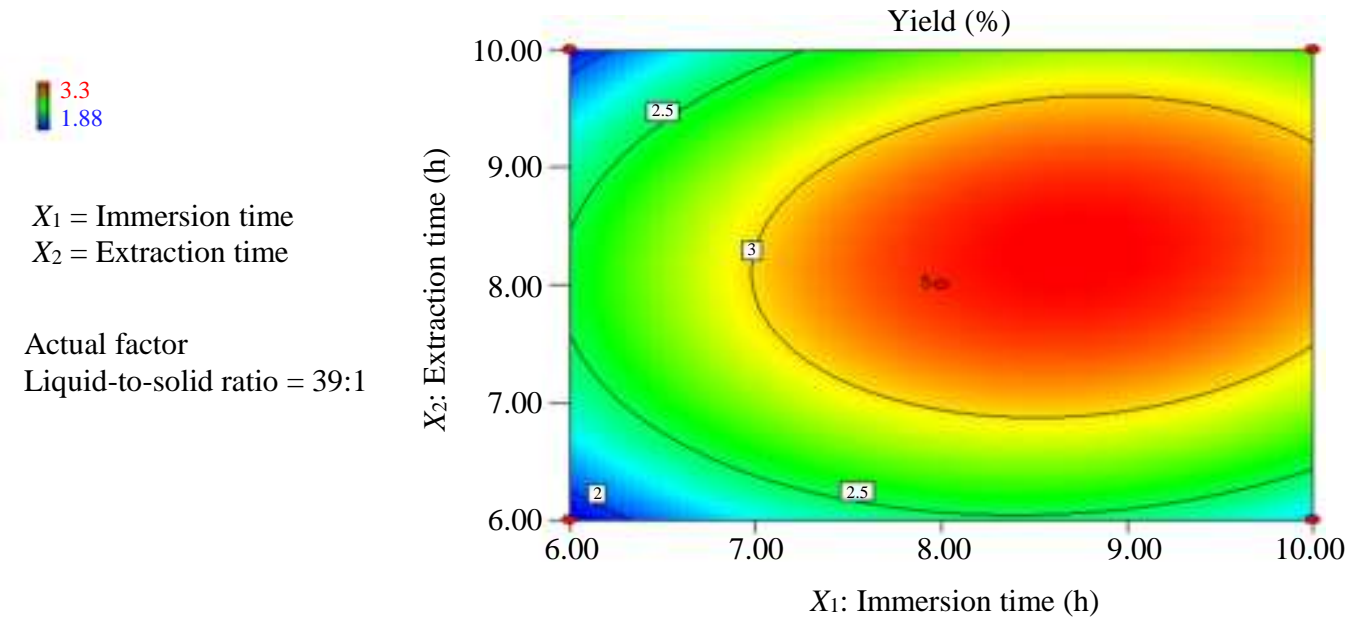

Fig. 4: Contour plot displaying the interaction effect of immersion time (h) and extraction time (h) on the yield of EODCJF

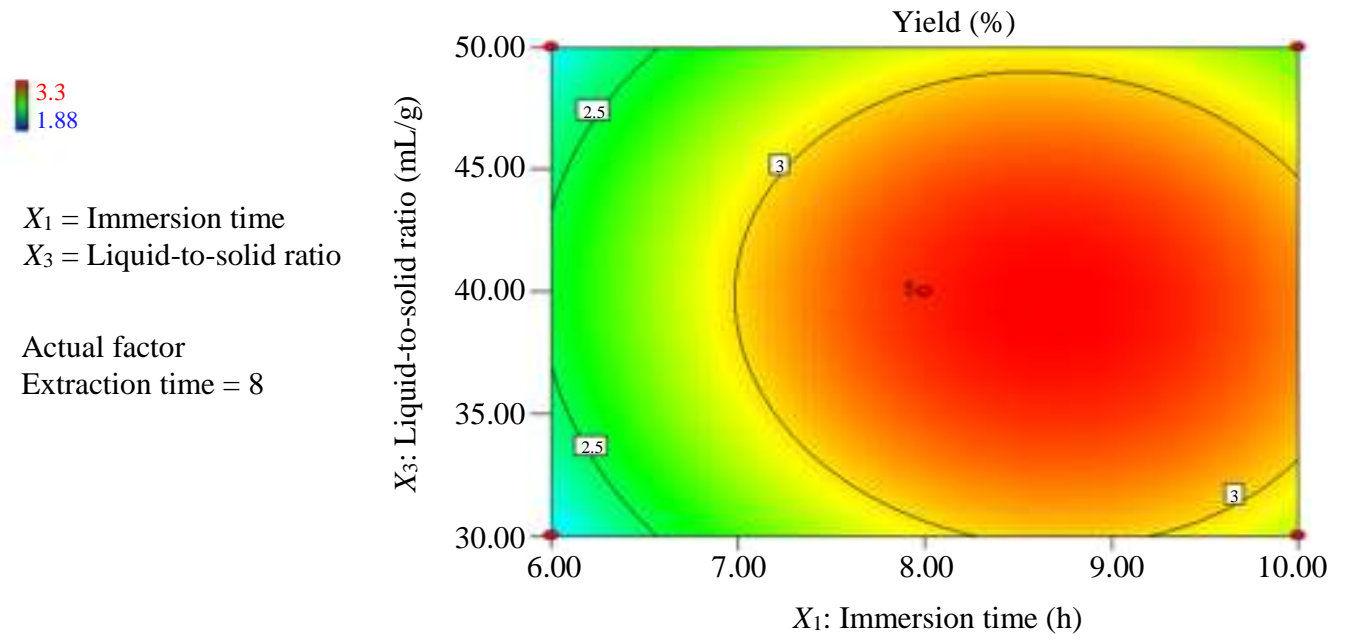

Fig. 5: Contour plot displaying the interaction effect of immersion time (h) and liquid-to-solid ratio (mL/g) on the yield of EODCJF

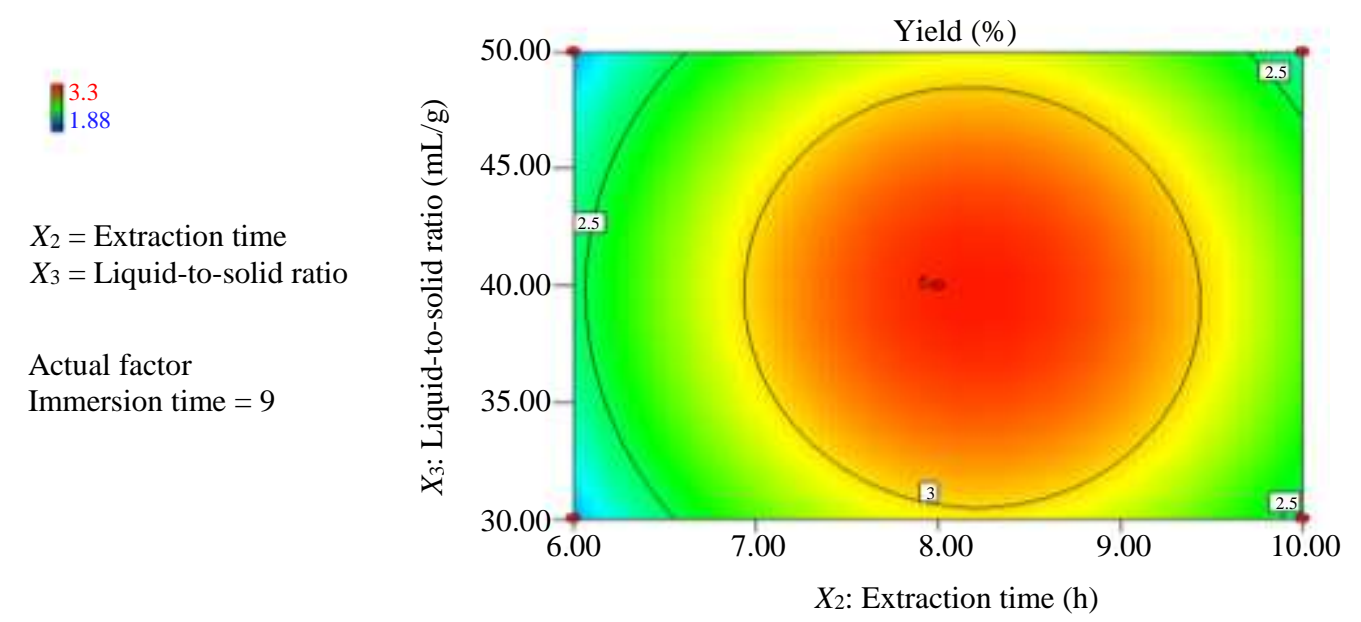

Fig. 6: Contour plot displaying the interaction effect of extraction time (h) and liquid-to-solid ratio (mL/g) on the yield of EODCJF 


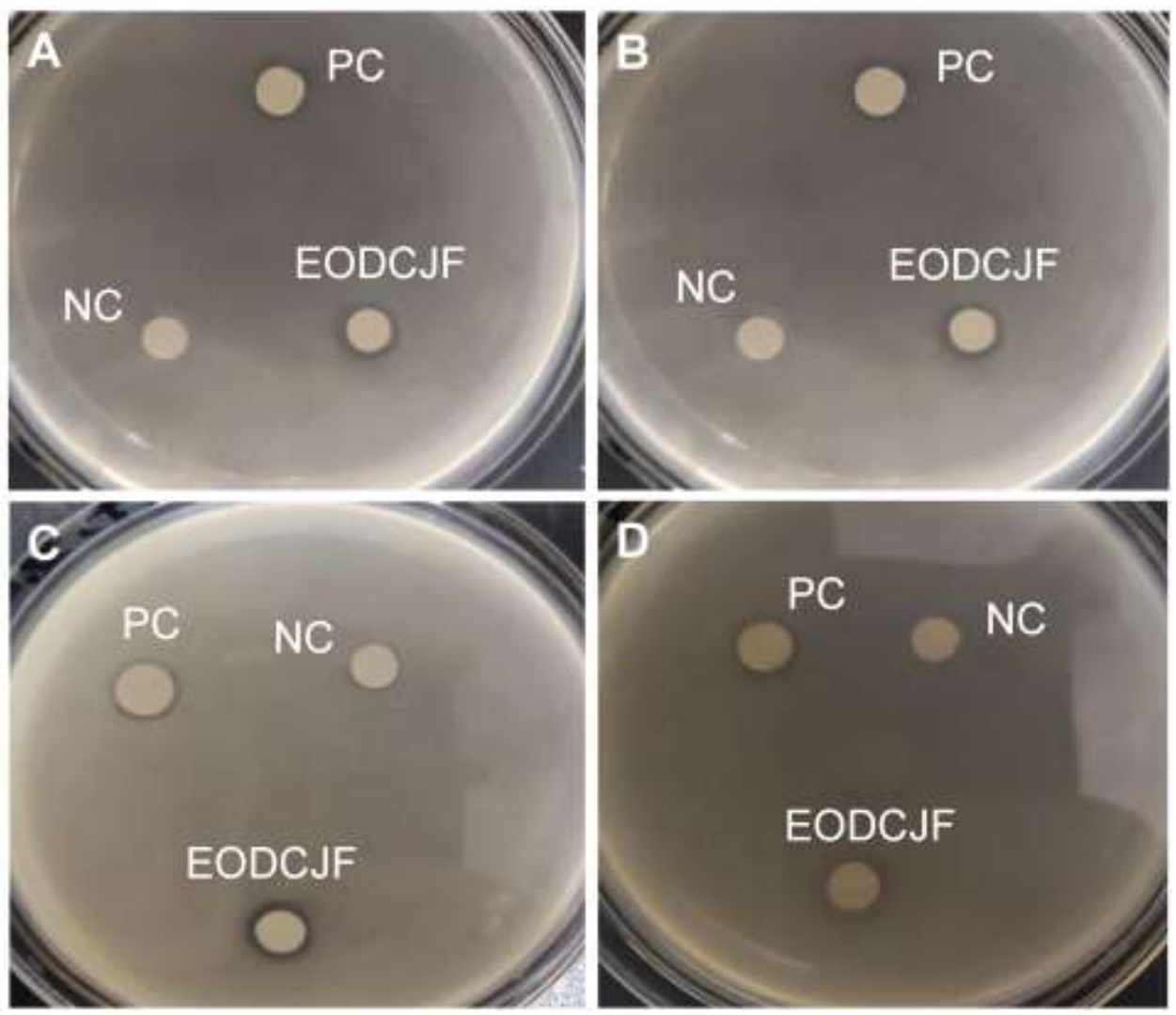

Fig. 7: Selected pictures of discs diffusion. A: E. coli; B: B. pumilus; C: B. subtilis; D: S. aureus.

\section{Discussion}

At the beginning, single-factor experiments for EODCJF extraction were conducted for obtaining the independent variables of RSM optimization. From Figs. 1 to 3, we can observe that prolonged pre-immersion and extraction time as well as overlarge liquid-tosolid ratio lead to a sharp decline in EODCJF yield. These unexpected phenomena could be explained by the following reasons: (1) pre-immersion of plant materials is beneficial for the dispersion of essential oils in water, thereby increasing extraction yield, however, overtime immersion before extraction would cause the loss of volatile compounds, leading to a decrease in extraction yield (Hui et al., 2015); (2) long-term hydrodistillation at water boiling temperature would alter the chemical compositions of essential oils and make certain substances that are vulnerable to heating degrade, thus causing a decline in extraction yield (Zheljazkov et al., 2014); (3) larger amount of water could result in an excessive swelling of raw materials to absorb some substances in EODCJF, leading to a decrease in extraction yield (Xiao et al., 2008).

Then, a three-factor-three-level RSM was achieved using BBD, followed by giving the predicted optimal parameters for EODCJF extraction. Under the predicted optimal extraction conditions, the actual yield of EODCJF was almostly equivalent to the predicted yield, and the error margin was smaller than $\pm 5 \%$, indicating that RSM coupled with BBD could be a feasible way to optimize the extraction parameters of EODCJF.

GC-MS was performed to disclose the chemical profile of EODCJF (Table 4). The major volatile ingredients in the Essential Oils from $C$. japonica Seeds (EOCJS) are quite different from those of EODCJF. $\alpha$-Terpineol, $\alpha$-terpenyl acetate, $\alpha$ terpinolene, $\alpha$-pinene and $\beta$-pinene were observed to be present more in EOCJS (Ramachandran et al., 2020). The significant differences on the chemical profiles of the essential oils derived from different parts of $C$. japonica would be due to the fact that biological components in plant are apt to assemble in a manner of tissue-specificity and different metabolic enzymes that are responsible for the modulation of secondary metabolites biosynthesis are expressed in different plant organs (Ji et al., 2016). Except C. japonica, variations on the essential oils from different parts for a same species were also found in Blumea balsamifera, Ruta chalepensis, Artemisia persica and so on (Tian et al., 2019). 
The antibacterial capacities of EODCJF against E. coli, B. pumilus, B. subtilis, and S. aureus could be partially contributed by their long-chain alcohols (Kubo et al., 1995). As summarized in Table 4, the total amount of alcohols in EODCJF was found to be $28.59 \%$ and overwhelming majority of them can be classified as long-chain alcohols. Meanwhile, according to similarity and intermiscibility principle, the abundant alkanes (Table 4) may ameliorate the dispersity of these liposoluble alcohols in EODCJF as benign solvents, thereby enhancing the interactions with test bacteria (Zheng et al., 2019). Whether or not EODCJF exerts inhibitory effects on other bacteria, such as fungus deserves further investigation. Besides, the determination of minimal inhibitory concentration and the underlying antibacterial mechanisms are equally needed to be explored.

\section{Conclusion}

In order to utilize the young dropped flowers of $C$. japonica, a commonly cultivated ornamental tree. In present investigation, the extraction optimization, chemical profile and antibacterial potential of EODCJF were explored for the first time. After being optimized by RSM and BBD, the yield of EODCJF increased up to $3.20 \%$. EODCJF elicited certain inhibitory effects on E. coli, B. subtilis, B. pumilus and $S$. aureus. The antibacterial capacity could be contributed by the long-chain alcohols present in EODCJF. Further studies are still pending: (1) Antimicrobial screenings with wider bacteria spectrum; (2) The underlying antibacterial mechanisms; (3) Fractionate EODCJF to disclose the structure-activity relationship; (4) Comparison on the chemical constituents with the essential oils from fresh $C$. japonica flowers, etc. It is hoped that this work would highlight the comprehensive utilization and development of wasted $C$. japonica flowers.

\section{Acknowledgement}

We appreciate Dr. Zhaowei Yan, Department of Pharmacy, The First Affiliated Hospital of Soochow University, Suzhou, China, for his assistance in interpreting the chemical profile of EODCJF.

\section{Funding Information}

This work was funded by the Jiangsu Provincial Undergraduate Innovation and Entrepreneurship Training Programs in 2020 (Grant No. 202010333062Y and 202010333060Y).

\section{Author's Contributions}

Yunqi Kong, Gaochao Wang and Xinyu Wang: Carried out the extraction and process optimization as well as wrote the paper.
Tong Wang, Jieyang Shen and Aibei Zhang: Performed the chemical profile and antibacterial assessment.

Yang Zhang and Lixue Zheng: Conceived the project and designed the experiments.

Yang Zhang: Revised and polished the manuscript.

\section{References}

Andrade, M. A., Braga, M. A., Cesar, P. H., Trento, M. V. C., Espósito, M. A., Silva, L. F., \& Marcussi, S. (2018). Anticancer properties of essential oils: an overview. Current Cancer Drug Targets, 18(10), 957-966.

Cheng, Z., Song, H., Cao, X., Shen, Q., Han, D., Zhong, F., ... \& Yang, Y. (2017). Simultaneous extraction and purification of polysaccharides from Gentiana scabra Bunge by microwave-assisted ethanol-salt aqueous two-phase system. Industrial Crops and Products, 102, 75-87.

Cui, H., Pan, H. W., Wang, P. H., Yang, X. D., Zhai, W. C., Dong, Y., \& Zhou, H. L. (2018). Essential oils from Carex meyeriana Kunth: Optimization of hydrodistillation extraction by response surface methodology and evaluation of its antioxidant and antimicrobial activities. Industrial Crops and Products, 124, 669-676.

Hui, R., Diao, Q., Hou, D., LI, T., \& Xiao, H. (2015). The influence of soaking time on volatile oil extraction research. Journal of Anshan Normal University, (2), 11.

Imane, N. I., Fouzia, H., Azzahra, L. F., Ahmed, E., Ismail, G., Idrissa, D., ... \& Noureddine, B. (2020). Chemical composition, antibacterial and antioxidant activities of some essential oils against multidrug resistant bacteria. European Journal of Integrative Medicine, 35, 101074.

Ji, A. J., Luo, H. M., Xu, Z. C., Zhang, X., Zhu, Y. J., Liao, B. S., ... \& Chen, S. L. (2016). Genome-Wide Identification of the AP2/ERF Gene Family Involved in Active Constituent Biosynthesis in Salvia miltiorrhiza. The plant genome, 9(2), 1-11.

Kim, M., Son, D., Shin, S., Park, D., Byun, S., \& Jung, E. (2019). Protective effects of Camellia japonica flower extract against urban air pollutants. BMC complementary and alternative medicine, 19(1), 30.

Kubo, I., Muroi, H., \& Kubo, A. (1995). Structural functions of antimicrobial long-chain alcohols and phenols. Bioorganic \& medicinal chemistry, 3(7), 873-880.

Lee, H. H., Cho, J. Y., Moon, J. H., \& Park, K. H. (2011). Isolation and identification of antioxidative phenolic acids and flavonoid glycosides from Camellia japonica flowers. Horticulture, Environment and Biotechnology, 52(3), 270-277. 
Lee, S. Y., Hwang, E. J., Kim, G. H., Choi, Y. B., Lim, C. Y., \& Kim, S. M. (2005). Antifungal and Antioxidant Activities of Extracts from Leaves and Flowers of Camellia japonica L. Korean Journal of Medicinal Crop Science, 13(3), 93-100.

Li, W., Zhang, C., Guo, X., Liu, Q., \& Wang, K. (2019). Complete chloroplast genome of Camellia japonica genome structures, comparative and phylogenetic analysis. PloS one, 14(5), e0216645.

Memarzadeh, S. M., Pirbalouti, A. G., \& AdibNejad, M. (2015). Chemical composition and yield of essential oils from Bakhtiari savory (Satureja bachtiarica Bunge.) under different extraction methods. Industrial Crops and Products, 76, 809-816.

Páscoa, R. N., Teixeira, A. M., \& Sousa, C. (2019). Antioxidant capacity of Camellia japonica cultivars assessed by near-and mid-infrared spectroscopy. Planta, 249(4), 1053-1062.

Piao, M. J., Yoo, E. S., Koh, Y. S., Kang, H. K., Kim, J., Kim, Y. J., ... \& Hyun, J. W. (2011). Antioxidant effects of the ethanol extract from flower of Camellia japonica via scavenging of reactive oxygen species and induction of antioxidant enzymes. International journal of molecular sciences, 12(4), 2618-2630.

Ramachandran, G., Rajivgandhi, G. N., Murugan, S., Alharbi, N. S., Kadaikunnan, S., Khaled, J. M., ... \& Li, W. J. (2020). Anti-carbapenamase activity of Camellia japonica essential oil against isolated carbapenem resistant klebsiella pneumoniae (MN396685). Saudi Journal of Biological Sciences, 27(9), 2269.

Sen, A., Kurkcuoglu, M., Bitis, L., Dogan, A., \& Baser, K. H. C. (2019). Chemical composition of endemic Stachys subnuda Montbret \& Aucher ex Benth. essential oil and its anti-inflammatory and antioxidant activities. Journal of Essential Oil Research, 31(4), 326-334.
Tian, H., Zhao, H., Zhou, H., \& Zhang, Y. (2019). Chemical composition and antimicrobial activity of the essential oil from the aerial part of Dictamnus dasycarpus Turcz. Industrial Crops and Products, 140, 111713.

Valdivieso-Ugarte, M., Gomez-Llorente, C., Plaza-Díaz, J., \& Gil, Á. (2019). Antimicrobial, antioxidant and immunomodulatory properties of essential oils: A systematic review. Nutrients, 11(11), 2786.

Xiao, W., Han, L., \& Shi, B. (2008). Microwaveassisted extraction of flavonoids from Radix Astragali. Separation and Purification Technology, 62(3), 614-618.

Yang, J. L., Ha, T. K. Q., Dhodary, B., Pyo, E., Nguyen, N. H., Cho, H., ... \& Oh, W. K. (2015). Oleanane triterpenes from the flowers of Camellia japonica inhibit porcine epidemic diarrhea virus (PEDV) replication. Journal of Medicinal Chemistry, 58(3), 1268-1280.

Zhang, J., Huang, R. Z., Cao, H. J., Cheng, A. W., Jiang, C. S., Liao, Z. X., ... \& Sun, J. Y. (2018a). Chemical composition, in vitro anti-tumor activities and related mechanisms of the essential oil from the roots of Potentilla discolor. Industrial Crops and Products, 113, 19-27.

Zhang, X., Guo, Y., Guo, L., Jiang, H., \& Ji, Q. (2018b). In vitro evaluation of antioxidant and antimicrobial activities of Melaleuca alternifolia essential oil. BioMed research international, 2018.

Zheljazkov, V. D., Astatkie, T., \& Schlegel, V. (2014). Hydrodistillation extraction time effect on essential oil yield, composition and bioactivity of coriander oil. Journal of oleo science, ess14014.

Zheng, L., Ben, L., Cui, Z., Fu, Q., Wang, L., Qi, B., \& Zhang, Y. (2019). The Phytol-rich Essential Oil from Fresh Medicago hispida Exerts Significant Inhibitory Activity against Escherichia coli. 